\title{
Effect of mass and turning time on free amino acid, peptide-N, sugar and pyrazine concentration during cocoa fermentation
}

\begin{abstract}
A response surface methodology (RSM) was used to determine the optimum condition for mass and turning time during cocoa fermentation. Mass and turning time were used as independent variables; concentrations of free amino acids, peptide- $\mathrm{N}$, sugars and pyrazines were the dependent variables. The Re values for peptide- $\mathrm{N}$, tetramethylpyrazine and total pyrazines were greater than 0.9 . Both lower $(10 \mathrm{~kg})$ and higher $(100 \mathrm{~kg})$ cocoa mass together with lower $(0 \mathrm{~min})$ and higher $(10 \mathrm{~min})$ turning time gave products containing low concentrations of hydrophobic, total and other free amino acids, peptide- $\mathrm{N}$, fructose, glucose and total reducing sugars; in contrast, those of acidic free amino acids gave higher concentrations. Trimethyl-, tetramethyl- and total pyrazines increased significantly $(\mathrm{P}<0.05)$ at higher mass $(100 \mathrm{~kg})$ and higher turning time $(10 \mathrm{~min})$. From the highest concentration of the important flavour precursors ie hydrophobic free amino acids, total reducing sugars and peptide-N, the recommended mass of cocoa beans and turning time for an optimum cocoa fermentation condition was $60 \mathrm{~kg}$ and $5 \mathrm{~min}$, respectively.
\end{abstract}

Keyword: Cocoa fermentation; Cocoa mass; Flavour precursors; Free amino acid; PeptideN; Pyrazine; Response surface methodology; Sugar; Turning time 